\title{
An Experimental Study of Unsteady Heat Transfer and Phase Changing Process Upon Impacting of Ice Crystals onto Heated Surfaces Pertinent to Aero-Engine Icing Phenomena
}

\author{
Haiyang Hu, Linchuan Tian, Hui Hu* \\ Department of Aerospace Engineering, Iowa State University, Ames, Iowa 50014, USA \\ *Corresponding authors: $\underline{\text { huhui@ iastate.edu }}$
}

\begin{abstract}
Extend Abstract
Ice accretion on exposed surfaces of aero-engine components has been widely recognized as a significant hazard to aviation safety in cold weathers. Icing process due to the impingement of the supercooled water droplets suspended in the cloud onto the cold surfaces of inlet components of aeroengines have been studied extensively for decades. Since ice particles were believed to simply bounce off from the exposed surfaces of aero-engine components, ice crystals in the clouds were initially considered not to pose a threat to aviation safety. Therefore, the ice accretion process due to the impacting of ice crystals onto the surfaces of hot engine componentes has not been studied until recently. It has been found recently that, tiny ice particles in the cloud may be partial/full melting upon impacting onto the hot surfaces of aero-engine components, such as heated Inlet Guide Vanes (IGV) and various probes. The partially/fully melted ice crystals were found to stick onto the hot surfaces and form thin water film, which would intercept more oncoming ice particles and lead to significant ice accretion over the surfaces of the hot engine components. The ice crystal induced ice accumulation on the critical aero-engine components has been found to cause significant engine performance loss and erroneous data being read from the probes.

In the present study, a series of experimental investigations were conducted to elucidate the underlying physics of the dynamic ice accretion process pertinent to ice crystal icing phenomena. A novel ice crystal icing test rig with the capacity of generating controllable amount of ice crystals and flying speed up to 100 $\mathrm{m} / \mathrm{s}$ was developed in a temperature-controllable environment chamber for the ice crystal icing studies. By using a high-speed imaging system, a digital particle image velocimetry(PIV), and an Infrared (IR) thermal imaging system, a comprehensive experimental campaign was performed to characterize the transient impacting process of ice crystals, dynamic ice accretion and unsteady heat transfer process associated with the impacting of ice crystals onto heated surfaces, in comparison to those due to the impingement of supercooled water droplets. By using an ultra-sensitive force sensor and a high-speed image system, a comparative study is conducted to examine the differences in the transient impinging dynamics of single water droplets, supercooled water droplets, and ice crystals onto solid surfaces with different wettability and stiffness. By upgrading the unique Icing Research Tunnel of Iowa State University (i.e., ISU-IRT) with additional ice crystal icing capability, a set of explorative studies are also conducted to examine the characteristics of the dynamic ice accretion processes over the heated surfaces of an aero-engine Inlet Guide Vane (IGV) model under both ice crystal icing and supercooled droplet icing conditions. The anti-/de-icing performance of a novel hybrid strategy by integrating icephobic coatings and minimized surface heating are also evaluated under both supercooled water droplet icing and ice crystal icing conditions. The new findings derived from the present studies are very helpful to gain further insights into the ice crystal icing phenomena for the development of more effective and robust anti-/de-icing strategies to ensure safer and more efficient aircraft/aero-engine operations in cold weathers.
\end{abstract}




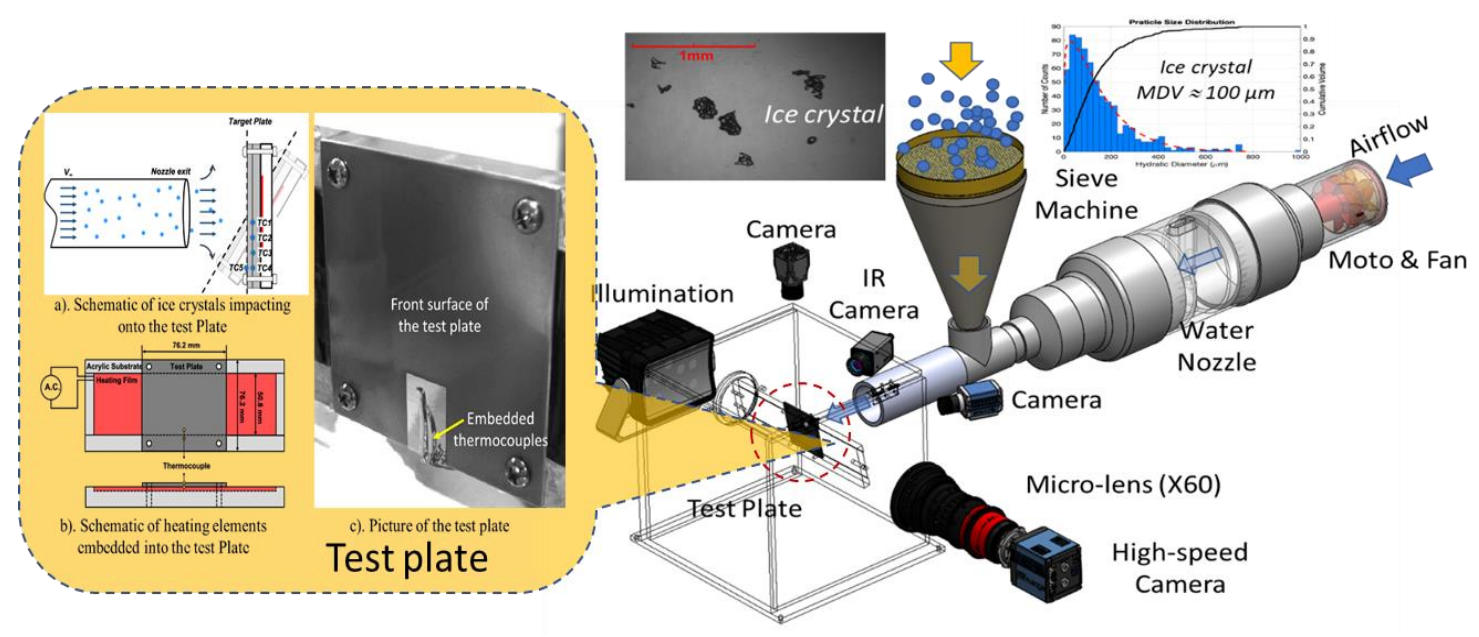

Fig. 1: Schematic of the ISU ice crystal icing test rig
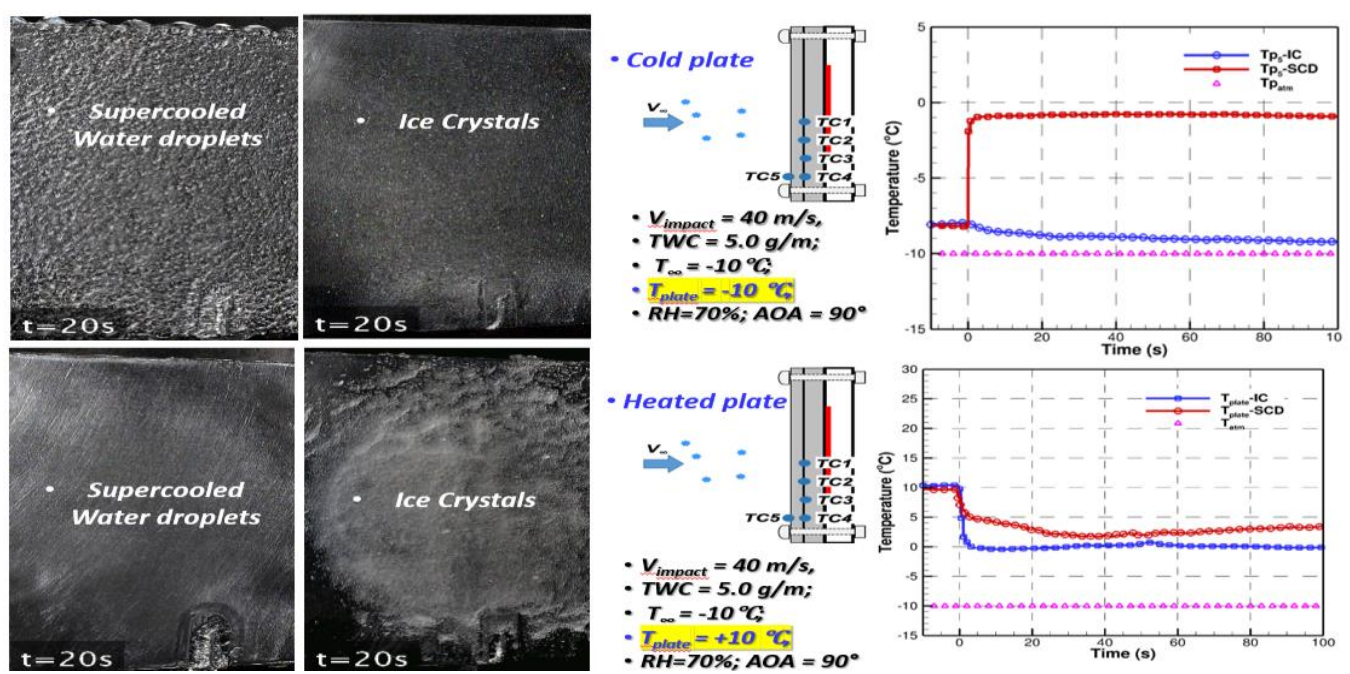

Fig. 2. Comparison of the impacting of supercooled water droplets and Ice Crystals onto a frozen-cold test plate and heated test plate
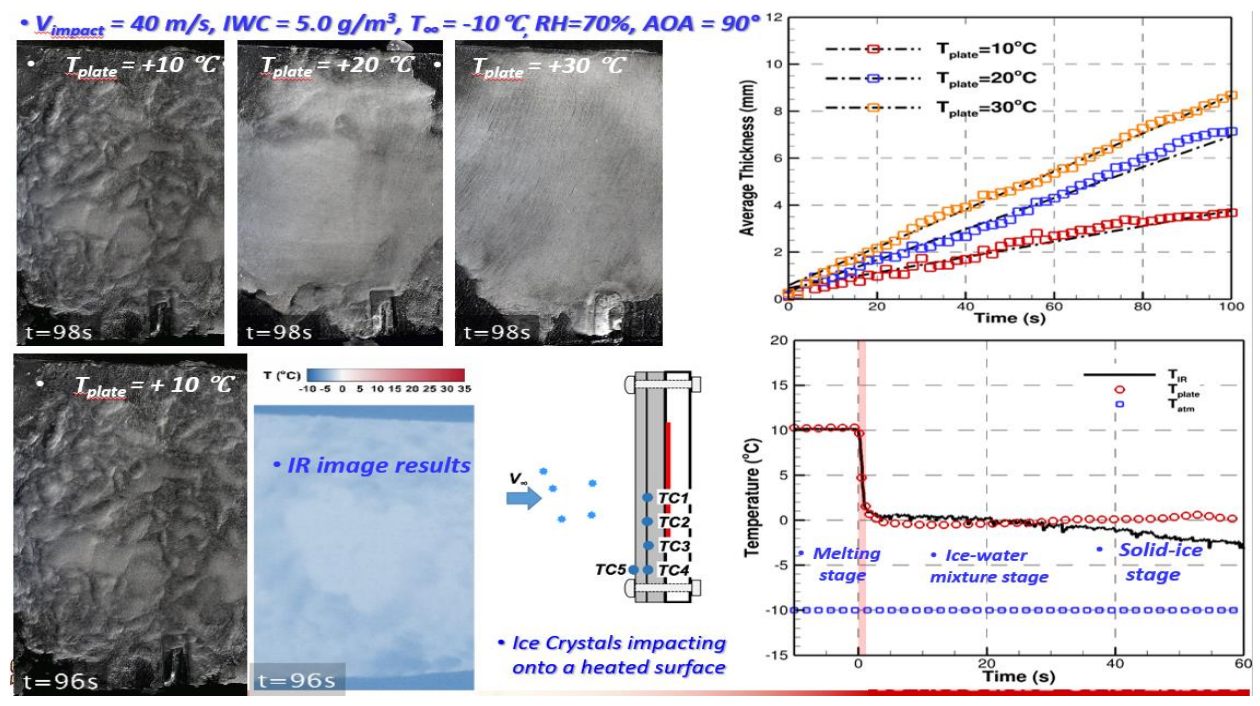

Fig.3. Effects of the temperature of the heated test plate on the ice critical icing process 